\title{
Profissão acadêmica: participação associativa e inserção em redes e em grupos de pesquisa - um inquérito em três universidades na amazônia brasileira
}

\author{
Academic profession: associative participation, network integration \\ and research groups - a survey in three universities in the Brazilian \\ Amazonian Region
}

Ana Celia Bahia Silva*

\section{RESUMO}

Este artigo apresenta parte dos resultados de investigação mais ampla, já concluída, sobre a reconfiguração da profissão acadêmica e as transformações no trabalho que professores universitários realizam, fazendo um recorte em resultados de uma pesquisa por questionário eletrônico, com uso de técnicas de amostragem probabilística. As dinâmicas de trabalho de professores universitários apresentam novos contornos e é relevante investigar como eles respondem a esse cenário, no qual elementos como a participação associativa e o trabalho em redes e em grupos de pesquisa são fatores importantes. O trabalho em redes científicas e de cooperação nacionais e internacionais está presente na atuação do professor universitário das IES pesquisadas e resulta em aumento da eficiência em projetos articulados, do acesso a recursos e aumento de publicações.

Palavras-chave: Profissão Acadêmica; Participação Associativa; Redes de Pesquisa; Grupos de Pesquisa.

\begin{abstract}
This paper presents part of the results of a more extensive research previously concluded about the reconfiguration of the academic profession and changes in the work that professors perform, through an approach on the results of an electronic survey, using probability sampling techniques. The dynamic work of university professors shows new outlines and it is relevant to identify how they respond to a scenario in which participation, networking and research groups play important roles. Working in scientific networks and in national and international cooperation makes its presence felt in the institutions whose professors were surveyed and the outcomes show an increased efficiency in articulated projects, access to resources and publications.
\end{abstract}

$\begin{array}{lcr}\text { Keywords: } & \text { Academic } & \text { Profession; } \\ \text { Associative } & \text { Participation; } & \text { Research } \\ \text { Networks; Research Groups. } & \end{array}$

\footnotetext{
* Doutora em Educação pela Universidade de Lisboa, Professora Titular na Universidade da Amazônia (UNAMA). Endereço: Avenida Alcindo Cacela, n² 287, Umarizal, CEP 66060-000, Belém - PA. Telefone: (91) 4009-3001 E-mail: anaceliabahia@hotmail.com / anacelia.bahia@unama.br
} 


\section{INTRODUÇÃO}

Desde os anos 80 vem crescendo a importância das redes de pesquisa, tanto as redes tradicionais de cooperação como as redes virtuais. Professores universitários sabem da importância das redes de cooperação científica para a organização do trabalho de pesquisa e produção científica, organização essa que integra grupos de pesquisa, que se articulam a outros grupos, configurando uma rede de relações.

$\mathrm{Na}$ concepção de Latour (1984) as redes constituem uma malha que articula as relações de instituições, grupos de pesquisa, laboratórios e cientistas, que realizam parcerias, trocas de informações, que articulam subvenções tendo em vista os frutos de pesquisa que podem gerar. Por exemplo, essa articulação pode gerar patentes, produtos, artigos comuns ou em colaboração, constituindo-se em uma estratégia tanto de aperfeiçoar recursos técnicos como para lidar com as exigências de produtividade.

O uso do sistema de grupos de pesquisa em rede como uma estratégia para chegar aos objetivos desejados quanto à publicação em revistas indexadas pode colocar esse objetivo em primeiro lugar. Esse artifício pode trazer efeitos danosos, como a fragmentação, o publicar por publicar, a indústria de publicações acadêmicas, um aparente progresso científico, como nos ensina Waters (2006, p.57) quando diz que "o estudioso típico parece cada vez mais com a figura retratada por Charlie Chaplin em seu 'Tempos Modernos', trabalhando louca e insanamente para produzir”.

Por outro lado há a questão da relação entre a produção, o financiamento, a autoria e a publicação, ao gerar associações artificiais que pretendem lidar com a racionalidade da produção em que os resultados e os processos são divididos, tal como na fábrica dos "Tempos Modernos", mas conducente a uma co-autoria artificial para fazer face às exigências do produtivismo.

Os grupos de pesquisa, sob a ótica do financiamento, são uma categoria de fomento que o Conselho Nacional de Desenvolvimento Científico e Tecnológico (CNPq) criou no Brasil. Pesquisadores são cadastrados e classificados de acordo com o sistema CNPq. Liderar ou participar de um grupo de pesquisa é vital para visibilidade e acesso a financiamento institucional ou mesmo individual mediante as bolsas de produtividade, daí a atividade de monitoramento da publicação de editais. Professores são então levados, pelo sistema de editais, a buscar fundos, e quanto mais bem sucedidos nessa tarefa mais tempo e energia dedicam em direção a atividades centrais que levam a isso.

Este artigo apresenta parte de resultados de investigação já concluída sobre as transformações no exercício da profissão acadêmica e está centrado em inquérito por questionário aplicado online, com uso de técnicas de amostragem probabilística.

A população alvo é constituída pelos professores efetivos de três universidades localizadas na região Amazônia, no Estado do Pará: uma federal (UFPA), uma estadual (UEPA) e uma particular (UNAMA). A amostra é de 340 professores, com erro amostral (C) 5,o. IC $=95 \%$ e Alfa $=5,0 \%$.

O estudo lançou mão do Teste Qui-Quadrado para estabelecer evidência estatística que indicasse relação entre variáveis e como um teste não paramétrico este pode ser utilizado visando avaliar a relação entre duas variáveis.

A estatística utilizada para sintetizar os resultados dos testes de hipóteses foi o valor $p, p$-valor ou nível descritivo. O valor-p é definido como a probabilidade de se observar um resultado tão ou mais extremo que o da amostra, supondo que a hipótese nula seja verdadeira. Testes de hipóteses com o valor $p$ inferior a 0,005 definem existência 
de relação entre as variáveis ou, dito de outro modo, o teste é significativo em um nível de $5 \%$. No caso do Teste Qui-Quadrado, rejeita-se a hipótese de que as variáveis são independentes, sendo elas associadas.

Os resultados são apresentados em estatísticas descritivas das variáveis em estudo a partir das questões de pesquisa contempladas nos ítens do questionário e em termos de relação de variáveis.

\section{UNIVERSO EMPÍRICO DA INVESTIGAÇÃO: 0 PERFIL DAS TRÊS UNIVERSIDADES}

O universo empírico da pesquisa teve como locus três universidades situadas na Amazônia brasileira, no estado do Pará. Diferentes contextos de desenvolvimento acadêmico influenciam diferenças entre universidades, tanto no que diz respeito a sua estruturação e organização interna como em relação ao desenvolvimento do trabalho acadêmico. A seguir passamos a uma breve apresentação das três IES com o objetivo de situar seus contextos institucionais, com dados (ano base 2009) relativos às dimensões de organização, oferta e características acadêmicas, obtidos em documentos divulgados pelas IES ou solicitados especialmente para a investigação.

\section{A Universidade Federal Do Pará (UFPA)}

É uma universidade pública federal, multi-campi com doze campi, doze Institutos, cinco Núcleos, cinquenta e um Polos Interiorizados, uma Escola de Aplicação e dois Hospitais Universitários. O Censo de Educação Superior de 2009 apontava a UFPA como a décima primeira universidade do Brasil em termos do número de alunos com 31.069 estudantes. Em 2009 era a universidade federal com o maior número de estudantes, pois as duas outras públicas no ranking das onze primeiras eram as estaduais USP e UNESP, e as demais eram todas do setor privado.

Entre 1999 e 2009 houve na UFPA um crescimento da pós-graduação stricto sensu que constou da passagem de 21 para 44 Mestrados, e de 06 para 19 Doutorados. A universidade possui 2.533 alunos nesses Programas o que revela um crescimento de $16,51 \%$ em relação ao ano de 2008 . Ainda assim é a décima primeira universidade do país na oferta de pós-graduação com apenas 1,4\% da oferta nacional. Vem desenvolvendo um conjunto de ações para elevação da proporção de professores doutores, programas de apoio à publicação qualificada, programa de apoio à cooperação interinstitucional e programas de avaliação dos cursos de graduação e das unidades administrativas e acadêmicas. Em 2009 desenvolvia 795 projetos de pesquisa envolvendo 824 docentes pesquisadores e concluiu 55 projetos com 88 docentes pesquisadores.

O corpo docente efetivo, sem considerar os professores substitutos e visitantes, é de 1869 professores com a seguinte configuração em termos de titulação e regime de trabalho considerando o total e o campus de Belém: 916 Doutores, 705 Mestres, 180 Especialistas e 68 Graduados. Desse total, 1552 têm regime de trabalho de Tempo Integral e Dedicação Exclusiva, 230 estão em Tempo Integral e 87 em Tempo Parcial. O corpo docente efetivo que atua em Belém é de 1558 professores, sendo 850 Doutores, 502 Mestres, 158 Especialistas e 48 Graduados. 


\section{A Universidade Do Estado Do Pará (UEPA)}

É uma universidade pública estadual, que nasceu de processo de fusão de Faculdades Estaduais em 1993, tendo sido autorizada a funcionar como universidade em abril de 1994. Tem estrutura multi-campi com cinco campi na capital e quinze campi e núcleos interiorizados. Em 2009 contava com 11.076 alunos de graduação, sendo 5.449 alunos matriculados em Belém e 5.627 nos núcleos interiorizados. Tem apenas dois cursos de Pós-Graduação Stricto Sensu: um Mestrado em Educação e outro em Biologia. Entretanto sedia um Doutorado Interinstitucional em Enfermagem e participa de outros Doutorados, Mestrados Acadêmicos e Mestrados Profissionais realizados em rede (Minter e Dinter).

Em termos de projetos de pesquisa em desenvolvimento em 2009 eram 36 na capital e 02 no interior, envolvendo um total de 58 bolsistas. Em relação a bolsas de Iniciação Científica o total era de 154 em 98 projetos, sendo 87 de programa financiado pela própria universidade, 30 financiadas pela Fundação de Apoio a Pesquisa do Pará (FAPESPA) e 37 financiadas pelo CNPq/PIBIC.

O Corpo Docente é composto de 688 professores efetivos e 424 temporários, atuando na capital e no interior. Entretanto os professores efetivos que atuam na capital são 623 dos quais 121 Doutores, 371 Mestres, 115 Especialistas e 15 Graduados, o que resulta no IQCD 3,15. Destes professores 31 (4,98\%) estão em regime de Tempo Parcial, 574 (92,13\%) em Tempo Integral e 18 (2,98\%) em Tempo Integral e Dedicação Exclusiva. Em 2008 realizou ampliação do quadro docente em 138 professores.

No programa de qualificação de professores, 152 estavam licenciados para realizar Pós-Graduação, sendo 38 em Mestrado, 113 e Doutorado e 01 em Pós-Doutorado.

O Plano Estratégico da Gestão que assumiu em 2009 estabeleceu objetivos estratégicos relacionados à implantação de política de pós-graduação, à criação de novos cursos que atendam a demanda da sociedade, ao aumento do quadro de docentes adequando-o à necessidade institucional, à ampliação do quadro de docentes com mestrado e doutorado, implantação de dois mestrados e um doutorado, à captação de recursos externos para pesquisa via editais, à criação de um programa de fixação de Doutores, ao aumento da produção científica e o número de professores com regime de tempo integral e dedicação exclusiva.

\section{A Universidade Da Amazônia (UNAMA)}

É uma universidade privada, criada em 1993, tendo origem na fusão de duas IES privadas - Faculdades Integradas e Centro de Estudos Superiores - existentes desde 1974 e que se uniram em 1988 para se transformarem em Universidade da Amazônia, o que ocorreu somente em 1993.

Possui quatro campi na capital, quatro Centros e o Instituto de Ciências Jurídicas. A matrícula de graduação em 2009 era da ordem de 10.046 alunos. Em termos de Pós Graduação Stricto Sensu oferece quatro Programas de Mestrado com 106 alunos matriculados. Não oferece Programa de Doutorado, entretanto integra consórcio de universidades em Programas de Doutorados Interinstitucionais (Dinter) com dois Doutorados. Possui seis Núcleos de Estudos e Pesquisa com oito áreas temáticas definidas como prioritárias e nesses Núcleos procura integrar um conjunto de professores em tempo integral com projetos de pesquisa, o que vem possibilitando a institucionalização da função pesquisa na universidade e o crescimento dos grupos com registro no Diretório do CNPq. Entretanto sua condição jurídica de universidade 
particular tem praticamente impedido o acesso a verbas de financiamento e fomento de pesquisa. Ao longo dos últimos dez anos tem destinado entre 1 e 1,5\% de seu orçamento anual para projetos de pesquisa.

O Corpo Docente é composto de 604 professores. Nele encontram-se 91 Doutores, 281 Mestres, 197 Especialistas e 35 Graduados, o que Ihe dá o IQCD 2,85. Esse quadro docente está assim distribuído em termos de regime de trabalho: 28 (4,64\%) em Tempo Parcial, 198 (32.78\%) em Tempo Integral e 378 (62,58\%) no regime Horista. Desenvolve política de qualificação docente sem apoio de recursos públicos e em 2009 estava com 96 professores em processos de formação em Mestrado e Doutorado.

\section{A Constituição dos Grupos de Pesquisa no Diretório do CNPq nas três Universidades.}

O Diretório de Grupos de Pesquisa no Brasil é uma Base de Dados que se constitui em uma plataforma de informação sobre Ciência e Tecnologia (C\&T), que organiza a informação e possibilita a gestão em C\&T. Tem a finalidade de fortalecer o intercâmbio entre pesquisadores brasileiros e estrangeiros; constituir-se em memória da atividade de pesquisa. Está integrado à Plataforma Lattes, que é o sistema de registro de currículos dos professores e pesquisadores. Assim é possível ter informações sobre os pesquisadores envolvidos nos grupos de pesquisa, as linhas de pesquisa, as especialidades, a produção de cada grupo pode ser acessada por região, por área de conhecimento entre outros indicadores.

Em termos de instituições, grupos e pesquisadores cadastrados no Diretório dos Grupos de Pesquisa do CNPq1, o Brasil cresceu entre os anos de 2000 e 2008, de 224 instituições para 422, de 11.760 grupos de pesquisa para 22.797 e de 48.781 para 104.018 pesquisadores. Mesmo que se considere que no período houve um aumento de instituições incluídas no levantamento e de sua taxa de cobertura no âmbito das instituições, é clara a tendência de crescimento. Ressalte-se, entretanto, que do total de 104.018 pesquisadores, apenas 1.763 estão na região Norte do Brasil e destes, 758 no Pará.

É relevante compreender como os grupos de pesquisa se constituem no espaço acadêmico também sob a influência das instituições de fomento e do mercado. A esse respeito, como bem assinalam Sguissardi e Silva Júnior.

[...] nos últimos anos começaram a se formar e reforçar nas IFES grupos ou segmentos alinhados aos novos campos da matriz do Estado configurada pela Agência CAPES, pelo CNPq e pelo mercado. E no interior da universidade, esses grupos têm na pósgraduação seu espaço privilegiado de atuação. (SGUISSARDI; SILVA JÚNIOR, 2009, p.183).

Em relação ao número de grupos de pesquisa com registro no Diretório de Pesquisa do Conselho Nacional de Desenvolvimento Científico e Tecnológico (CNPq) revela-se a existência de 258 grupos pela UFPA, 48 pela UNAMA e 28 pela UEPA, conforme a seguinte distribuição por grande área de conhecimento.

1'Disponível em: www.cnpq.br. Acesso em: 23 maio 2010. 
Tabela 1 - Grupos de Pesquisa com registro no Diretório de Grupos de Pesquisa do CNPq

\begin{tabular}{|c|c|c|c|c|}
\hline Grande Area de Conhecimento & UFPA & UE PA & UNAMA & TOTAL \\
\hline $\begin{array}{l}\text { Ciências da Natureza } \\
\text { - Eng enharias e C. Computaçào }\end{array}$ & 30 & 02 & 05 & 37 \\
\hline - Ciências da Terra & 40 & 02 & - & 42 \\
\hline Sub Total & 70 & 04 & 05 & 79 \\
\hline $\begin{array}{l}\text { Ciências da Vida } \\
\text { - Ciências da Saúde }\end{array}$ & 24 & 09 & 05 & 38 \\
\hline - Ciências Biológicas & 30 & - & 01 & 31 \\
\hline - Ciências Agrárias & 08 & 01 & - & 09 \\
\hline Sub Total & 62 & 10 & 06 & 78 \\
\hline $\begin{array}{l}\text { Humanid ades } \\
\text { - Ciências Humanas }\end{array}$ & 77 & 12 & 12 & 101 \\
\hline - Ciências Sociais Aplicadas & 25 & 01 & 22 & 48 \\
\hline - Linguistica, Letras e Artes. & 24 & 01 & 03 & 28 \\
\hline Sub Total & 126 & 14 & 37 & 177 \\
\hline Total & 258 & 28 & 48 & 334 \\
\hline
\end{tabular}

Fonte: Elaborado pela autora a partir de dados do Diretório de Grupos de Pesquisa do CNPq e das IES.

Portanto a entrada da universidade na lógica das agências de fomento, a consolidação da pós-graduação, o número de doutores e o regime de tempo integral prevalente na UFPA fazem com que os grupos de pesquisa tenham se ampliado e se consolidado, não sem disputas de espaço nos órgãos de financiamento e da competividade que se instaura. Participar de um grupo de pesquisa, obter bolsas de produtividade e garantir verbas nos editais de financiamento, acaba por instaurar também um sistema de castas, no qual se relacionam tais condições ao prestígio acadêmico. Por outro lado, os números constantes do quadro acima revelam a potência e a potencialidade da UFPA em termos de produção científica e seu papel central no Estado do Pará.

\section{INQUÉRITO COM PROFESSORES UNIVERSITÁRIOS}

\section{Perfil dos professores universitários participantes do inquérito.}

A profissão acadêmica é heterogênea em termos das áreas de conhecimento, do tipo de atividade na qual o professor centra a sua carreira, do tipo de contrato, do regime de trabalho e no tempo de carreira. Há uma diversificação interna na profissão acadêmica e convivem na universidade diversos tipos de perfis de professores.

Realizar o trabalho acadêmico em uma universidade ou em uma instituição não universitária também configura a carreira e o perfil do professor e há uma tendência de crescente diversificação de tipos de instituições a influenciar a ampliação da diversificação da profissão acadêmica.

Essa ampliação da diversificação interna da profissão acadêmica (SALA, 2002; MUSSELIN, 2008) ou de reconfiguração do ofício acadêmico (GALAZ FONTES; GIL ANTON, 2009) não resulta apenas das diferenças oriundas dos campos de 
conhecimento e das culturas acadêmicas. Resulta também da expansão dos sistemas de ensino superior, da diversificação de tipos de IES e das políticas governamentais e institucionais (BALBACHEVSKY; SCHWARTZMAN, 2007), bem como das características que as IES assumem, ou seja, os "contextos institucionais" (BALBACHVESKY, 1999), uma vez que o ambiente institucional em que estão os professores e sua interação com e nestes contextos, promove a diferenciação dos profissionais da academia.

Consideramos relevante um olhar sobre o perfil dos professores participantes do inquérito, pois estas características podem influenciar seu posicionamento ao responder ao questionário. No inquérito foram pesquisados 340 professores de três universidades, sendo 76 (22,35\%) da UEPA, 75 (22,06\%) da UNAMA e 189 (55,59\%) da UFPA. Do total, 59,4\% são Doutores, 33,0\% são Mestres, 4,7\% são Especialistas e 2,9\% são Graduados.

O Plano Amostral previa também que amostra aleatória estratificada proporcional distribuída de forma proporcional ao número de docentes em cada nível de titulação. Desse modo, o inquérito previa a participação de 12 graduados, 57 especialistas, 140 mestres e 129 doutores. Todavia o retorno dos questionários alterou discretamente essa previsão, ficando a amostra real com 340 professores dentre 10 graduados, 50 especialistas, 143 mestres e 137 doutores conforme está indicado em termos percentuais a seguir.

Figura 1 - Titulação por IES

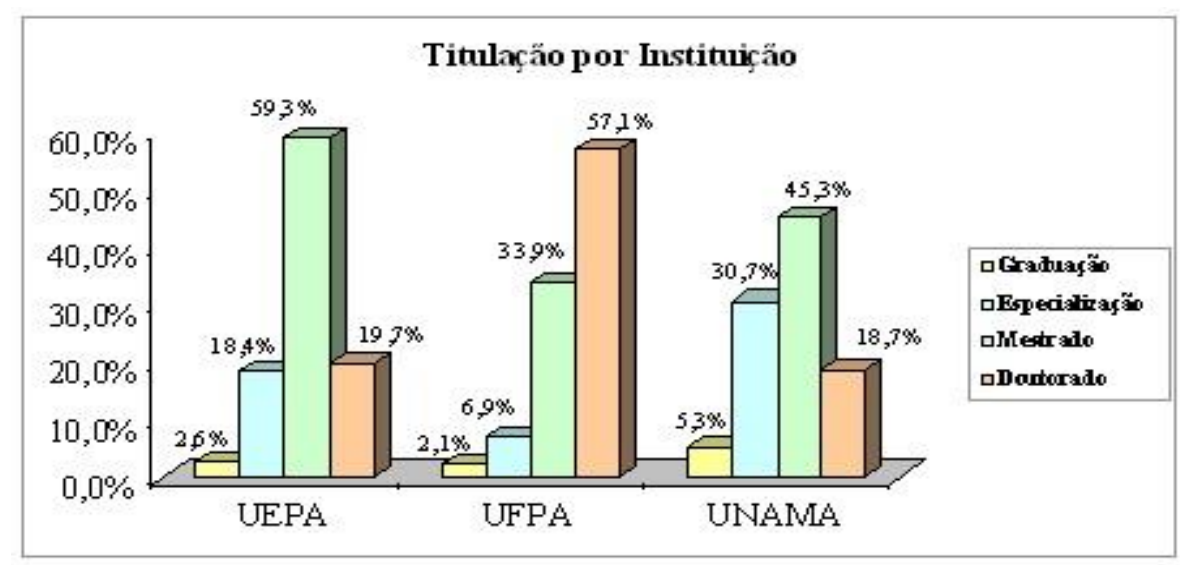

Fonte: Elaborado pela autora.

Dos 137 Doutores participantes apenas $26(18,9 \%)$ concluíram Pós Doutorado, sendo que $10(38,4 \%)$ o realizaram no Brasil e $16(61,5 \%)$ no exterior. Ressaltamos que o Pós Doutorado não provoca alterações na carreira em termos de salário, mas é uma estratégia de abertura de contatos acadêmicos tendo em vista a pesquisa, a continuidade da produção científica ao mesmo tempo em que potencializa o trabalho acadêmico em decorrência das articulações que possibilita.

Regime de trabalho e qualificação acadêmica são dois fatores essenciais ao exercício da profissão acadêmica sendo inclusive a base da profissão em termos internacionais. A proporção de doutores no corpo acadêmico é outra característica associada. Em termos de regime de trabalho o inquérito atingiu 163 (47,9\%) professores com Tempo Integral e Dedicação Exclusiva (TIDE), 136 (40\%) em Tempo Integral (TI) e 141 (12,1\%) em Tempo Parcial (TP). 
Por universidade revela-se predominância do regime de Dedicação Exclusiva na UFPA que, tal como a maioria das federais, praticamente fez deste regime a regra. Assim também tem essa universidade o maior percentual de professores com o título de Doutor no corpo docente, combinando portanto alta titulação e alto tempo de dedicação, o que não é característica das duas outras universidades pesquisadas. É possível associar tal condição a um ambiente institucional de estímulo à pesquisa, expresso nos 258 grupos de pesquisa registrados no Diretório do CNPq e nos 19 programas de pós-graduação stricto sensu.

A Pós-Graduação stricto sensu consolidada está associada ao desenvolvimento da pesquisa. Por outro lado as duas outras universidades não tendo essa condição, têm menor participação em termos de grupos de pesquisa e baixa oferta de pósgraduação stricto sensu.

É necessário registrar que nas três universidades não compuseram a amostra professores temporários, substitutos ou horistas, visto que tanto a efetividade como o regime de trabalho estável são condições essenciais ao exercício da profissão acadêmica nas funções de ensino, pesquisa e extensão, e na perspectiva de que aqueles professores têm dedicação somente para a função ensino ou pelo menos são contratados nessa perspectiva.

As três universidades compreendem áreas de conhecimento a que estão associadas às unidades universitárias nas quais estão lotados os professores. Assim, as grandes áreas das Ciências da Natureza, Ciências da Vida e Humanidades estão assim representadas no inquérito, respectivamente, por $24,1 \%, 25,6 \%$ e $50,3 \%$ dos professores participantes do inquérito.

A predominância da área de Humanidades é proporcional ao tamanho do quadro docente desta área nas universidades pesquisadas, ou seja, somente esta área possui o maior número de unidades universitárias em todas as IES pesquisadas e bem assim o maior número de professores em cada IES. A vantagem de ter uma amostra das diferentes áreas de conhecimento está na significação das respostas em termos de representatividade.

A faixa etária dos respondentes está entre 26 anos (mínima) e 67 anos (máxima) anos e a média é de 47,9 anos evidenciando que o inquérito cobriu uma faixa etária diversificada. O questionário solicitava a indicação do ano de nascimento do professor e a partir das respostas indicadas estabelecemos quatro faixas para enquadramento: a Faixa 1 que compreende professores entre 26 e 35 anos com 9,4\%, a Faixa 2 com professores entre 36 e 45 anos com 32,3\%, a Faixa 3 de 46 a 55 anos com $36,5 \%$ e a Faixa 4 de 56 a 67 anos com $21,8 \%$, correspondentes aos intervalos de anos de nascimento.

O questionário solicitava informação sobre o ano de ingresso na carreira acadêmica e as respostas obtidas variaram desde o ano de 1969 até 2009, ou seja, desde professores com um ano na carreira acadêmica até professores com 40 anos na carreira, o que significa que o inquérito pesquisou desde professores em início, a professores em final de carreira. Optamos por agrupar em quatro faixas, compreendendo como Início de Carreira (1 a 5 anos), Anos Intermediários (6 a 15 anos), Anos de Estabilização (16 a 25 anos) e Anos Finais (26 anos ou mais). A média de tempo de carreira é 16,8 anos, o maior tempo de carreira é de 40 anos. 
Figura 2 - Tempo de Carreira

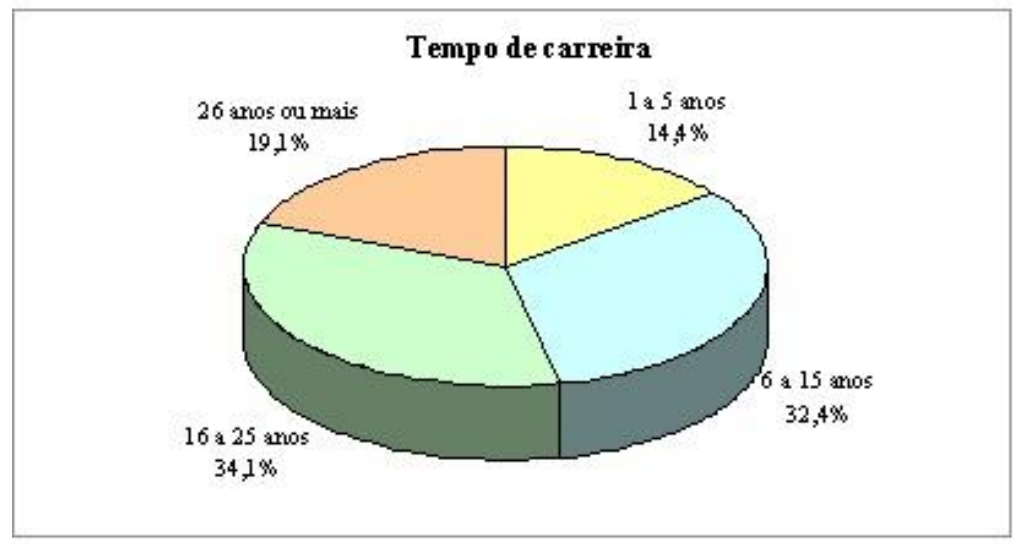

Fonte: Elaborado pela autora.

As credenciais em termos de titulação de ingresso e de progressão na carreira acadêmica variam no tempo; entretanto, nos últimos dez anos, conforme Balbachevsky (2007, p.188) concluiu, em estudo sobre carreira e titulação entre 1992 e 2003, há uma desorganização crescente na estrutura da carreira nas IES brasileiras e um enfraquecimento da relação entre titulação e carreira:

[...] a carreira oferecida pelas IES está pouco a pouco perdendo a capacidade de discriminar e recompensar o desempenho acadêmico já que o principal referencial a partir do qual ela foi constituída - a titulação - tende nos últimos anos a se homogeneizar. A progressão na carreira ocorre mediante titulação, tempo de serviço e avaliação, ou seja, a obtenção de títulos acadêmicos de Mestrado e Doutorado e, no interstício de dois anos em cada nível da carreira um processo de avaliação de desempenho. (BALBACHEVSKY, 2007, p.188)

Quanto à titulação de ingresso na carreira acadêmica os dados revelam que somente 6,5\% dos professores possuíam o título de Doutor. O título ao nível da Graduação ou da Especialização foi para a maioria dos pesquisados, suficiente para ingresso na carreira. Entretanto na medida em que as universidades implantam programas de mestrado e doutorado e surgem as exigências dos dispositivos legais de um terço de mestres e doutores para as universidades, observa-se a relevância de um corpo docente titulado em nível de mestrado e doutorado. Para Balbachevsky (2007, p.185) "o crescimento da pós-graduação, as exigências pós-LDB e os parâmetros de avaliação criam um cenário mais complexo". Além disso, é importante ressaltar a associação entre titulação (qualificação) e posição acadêmica e, bem assim, na capacidade de captação de recursos externos para pesquisa, na medida em que um corpo docente altamente titulado e qualificado tem maiores chances de sucesso nesta busca por recursos.

A tabela a seguir apresenta a titulação de ingresso na carreira considerando as IES e evidencia que há uma associação entre as variáveis 'titulação de ingresso' e 'tipo de IES'. A universidade privada e a universidade estadual apresentam-se como menos exigentes em termos de titulação de ingresso, pelo menos para os professores inquiridos. 
Tabela 2 - Titulação de ingresso na carreira segundo a IES

\begin{tabular}{l|c|c|c|c}
\hline \multirow{2}{*}{ Titulaçào de ingresso na Carreira } & UEPA & UFPA & UNAMA & TOTAL \\
\cline { 2 - 5 } & $\%$ & $\%$ & $\%$ & $\%$ \\
\hline Graduação & 34,2 & 39,7 & 33,3 & 37,1 \\
\hline Especialização & 40,8 & 19,6 & 49,4 & 30,9 \\
\hline Mestrado & 25,0 & 29,6 & 16,0 & 25,6 \\
\hline Doutorado & 0,0 & 11,1 & 1,3 & 6,4 \\
\hline Total & 100,0 & 100,0 & 100,0 & 100,0 \\
\hline Valor p $=0,000$
\end{tabular}

Fonte: Elaborado pela autora.

A flexibilidade que os professores universitários têm, como empregados públicos ou privados, permite-lhes outros contratos ou vínculos acadêmicos ou técnicos e desse modo podem exercer atividades paralelas à sua ocupação na universidade, principalmente aqueles vinculados a áreas de conhecimento e cursos das profissões liberais tais como Direito, Administração ou Medicina. Também o regime de tempo parcial possibilita ter outro contrato de trabalho na mesma ocupação, ou seja, na atividade acadêmica ou em outra atividade profissional. É o caso da UNAMA e da UEPA que têm respectivamente $61,37 \%$ e $60,5 \%$ dos professores participantes do inquérito com outros vínculos de trabalho, enquanto que na UFPA, 81,5\% possuem contrato somente com a universidade e este dado aproxima-se do índice de $83,1 \%$ de professores em regime de tempo integral e dedicação exclusiva.

Examinar se os professores têm um ou mais vínculos contratuais e se esses vínculos adicionais são na área acadêmica, pública ou privada, ou com empresas públicas ou privadas pode possibilitar a compreensão de aspectos relacionados à carga de trabalho, à distribuição das atividades em ensino, pesquisa, extensão e gestão, bem como a dedicação focada na área acadêmica ou não, concentrada em uma só IES ou não.

Tabela 3 - Contrato de Trabalho segundo a IES

\begin{tabular}{l|c|c|c|c}
\hline \multirow{2}{*}{ Contrato de Trabalho } & UEPA & UFPA & UNAMA & TOTAL \\
\cline { 2 - 5 } & $\%$ & $\%$ & $\%$ & $\%$ \\
\hline Somente com uma IES & 39,5 & 81,5 & 38,7 & 62,7 \\
\hline Com outra IES (pública) & 11,8 & 2,1 & 9,3 & 5,9 \\
\hline Com outra IES (privada) & 25,0 & 6,9 & 14,7 & 12,6 \\
\hline Com empresa pública ou privada & 23,7 & 9,5 & 37,3 & 18,8 \\
\hline Total & 100,0 & 100,0 & 100,0 & 100,0 \\
\hline Valor $\mathrm{p}=0,000$
\end{tabular}

Fonte: Elaborado pela autora.

\section{Participação associativa e inserção em redes e grupos de pesquisa.}

A participação associativa, segundo Schwartzman (1997), é uma das características das profissões e relaciona-se à expressão de uma identidade profissional comum. Também Becher e Trowler (2001) referem que a participação dos acadêmicos em associações científicas ou profissionais, a participação em eventos, a atualização e a troca de resultados que os eventos promovidos possibilitam, são um referencial 
importante para a profissão. Procuramos sondar elementos sobre a participação associativa do professor, ou seja, sua filiação a associações acadêmicas, profissionais e sindicais e os resultados evidenciam que somente $20,9 \%$ não pertencem às associações. A Associação Sindical está mais presente na universidade federal (49,7\%) e na universidade privada $(55,0 \%)$ do que na universidade estadual $(28,9 \%)$. Observese também que a associação a entidades internacionais tanto no âmbito acadêmico quanto no profissional é baixa, respectivamente com 8,5 e 4,7\%, o que pode ser um dos fatores que contribuem para que os professores tenham dificuldade de publicar em periódicos internacionais.

Tabela 4 - Participação Associativa

\begin{tabular}{l|c}
\hline \multicolumn{1}{c|}{ Participação Associativa } & $\%$ \\
\hline Associação/ Sindicato Docente & 49,7 \\
\hline Associação Acadêmica Nacional & 27,9 \\
\hline Associação Acadêmica Internacional & 8,5 \\
\hline Associação Profissional Nacional & 34,1 \\
\hline Associação Profissional Internacional & 4,7 \\
\hline Năo pertence a tais Associações & 20,9 \\
\hline
\end{tabular}

Fonte: Elaborado pela autora.

O envolvimento em redes científicas e de cooperação, nacionais e internacionais, é algo essencial nos novos modos de produção do conhecimento e é academicamente valorizado. $O$ desenvolvimento de projetos nacionais e internacionais articula equipes de professores e trazem importantes formas de trabalho que possibilitam compartilhar recursos, conhecimento, tecnologia e favorecer relações com agências financiadoras. Estar ou não inserido em tais redes significa também prestígio acadêmico-científico e a possibilidade de influenciar ou ser influenciado.

Há também a análise da questão da circulação dos acadêmicos nas redes e a influência desta circulação na disseminação de ideias. Rhoades e Sporn (2002) discutem essa questão dos modos pelos quais as profissões e os professores exercem influências nas redes internacionais e a forma pelas quais os profissionais das chamadas nações de desenvolvimento industrial avançado influenciam as políticas e as práticas em termos de educação superior e quais mecanismos utilizam, nessas redes profissionais, nas publicações, como consultores e na circulação global. E citam o trabalho de tese de Maldonado (2004, p.138) sobre a influência das organizações internacionais no campo da educação superior no México, a indicar que nos países em desenvolvimento funcionam mecanismos que podem "ser um pouco diferentes, tais como a inter-relação entre organizações como o Banco Mundial e os centros nacionais de políticas de educação superior".

A inserção em redes de pesquisa e cooperação pode ser uma condição importante para a produção científica tendo em vista agilizar a produção e a publicação. Os resultados do inquérito revelam que a participação dos professores em redes de pesquisa e cooperação é algo presente, mas não marcante, pois 52,6\% participam de redes e 47,4\% não participam. Quando há participação, esta é maior em redes nacionais $(37,9 \%)$ e menor em redes internacionais $(3,8 \%)$. 
As razões indicadas por $52,6 \%$ dos professores estão relacionadas ao aumento de eficiência do trabalho e pelas articulações que possibilitam a produção científica e o compartilhamento de recursos. A tabela a seguir apresentada indica além desta, as demais razões:

Tabela 5 - Razões indicadas para participação em redes científicas e de cooperação

\begin{tabular}{|c|c|}
\hline Razões & $\%$ \\
\hline $\begin{array}{l}\text { Facilita o estabelecimento de relação formal e permanente com ag ências de apoio } \\
\text { à ciência, tecnologia e inovaçào e órgàos de financiamento. }\end{array}$ & 6,7 \\
\hline $\begin{array}{l}\text { Pelo aumen to de eficiência, pois a colaboração possibilita a realizaçào de } \\
\text { projetos conjuntos com uso de pessoal e infraestrutura, agreg ando esforços, } \\
\text { fortalecendo a pesquisa na temática da rede econgregando experiencia. }\end{array}$ & 34,1 \\
\hline $\begin{array}{l}\text { Por que é o meio mais eficiente de lidar com projetos complexos em ambientes de } \\
\text { rápida mudança tecnolog ico-cientifica. }\end{array}$ & 3,3 \\
\hline $\begin{array}{l}\text { Como uma estrategia para poder ampliar as possibilidades de produção, } \\
\text { publicaçào, acesso a editais, ou seja, aumen to de vantagem competitiva. }\end{array}$ & 15,6 \\
\hline $\begin{array}{l}\text { Pelo prestig io acadêmico-cientifico e profissional que as redes possibilitam. } \\
\text { Quem nâo está em rede está "fora do circuito". }\end{array}$ & 1,7 \\
\hline $\begin{array}{l}\text { Pelas articulações que possibilitam o desenvolvimen to do trabalho de produção } \\
\text { cientifica, o compartithamento de recursos e o alinhamento a fontes externas de } \\
\text { fomento. }\end{array}$ & 21,8 \\
\hline $\begin{array}{l}\text { Compartilhar conhecimentos, tecnologia e inovação com aproveitamento de } \\
\text { infraestrutura e recursos humanos, evitar sobreposição, descentralizar. }\end{array}$ & 16,8 \\
\hline Total & $100 \%$ \\
\hline
\end{tabular}

Fonte: Elaborado pela autora.

Ao analisarmos a correlação entre participação em redes por IES observamos, na tabela a seguir, o valor $p=0$, 001 que permite rejeitar a hipótese de independência entre as variáveis. Também o valor $p=0,002$ na razão que justifica a participação nos permite a mesma conclusão. Quando analisamos por IES observa-se uma prevalência, na universidade privada, da não participação em redes de pesquisa e cooperação. É a que tem também a menor inserção em redes internacionais, o que pode ser explicado pela não prevalência do regime de tempo integral, da menor densidade de doutores da IES e de uma menor dedicação de tempo à pesquisa.

\section{Tabela 6 - Relação entre participação em redes científicas de pesquisa e de cooperação e tipo de IES}

\begin{tabular}{l|c|c|c|c}
\hline \multicolumn{2}{c|}{$\begin{array}{c}\text { Participação em redes cientiffic as de pesquisa e de } \\
\text { coopera ção }\end{array}$} & \multicolumn{3}{c}{ Instituicão \% } \\
\cline { 2 - 5 } $\begin{array}{l}\text { Não participam de rede cientifica de pesquisa e de } \\
\text { cooperação }\end{array}$ & 52,6 & 38,1 & 65,4 & 47,4 \\
\hline Participam de rede internacional & 2,6 & 5,3 & 1,3 & 3,8 \\
\hline Participam de rede nacional & 39,5 & 40,7 & 29,3 & 37,9 \\
\hline Participam de rede nacional e internacional & 5,3 & 15,9 & 4,0 & 10,9 \\
\hline$\%$ & 100,0 & 100,0 & 100,0 & 100,0 \\
\hline Valor $\mathrm{p}=0,001$ &
\end{tabular}

Fonte: Elaborado pela autora. 
A organização do trabalho acadêmico para a produção científica por meio de grupos de pesquisa, constituídos por um ou mais líderes, pesquisadores, alunos de mestrados, doutorados e pós-doutorandos que se articulam em torno de uma temática comum ou de um programa comum, é frequente nas universidades e centros de pesquisa.

A participação em Grupos de Pesquisa com registro no Diretório de Grupos de Pesquisa do CNPq é significativa, pois somente $38,8 \%$ não registram essa participação. Para além da importância dos Grupos de Pesquisa nos processos de institucionalização da pesquisa em cada universidade, a participação e o interesse no registro formal está também associada a sua valorização tanto na avaliação de cursos e programas de pós-graduação como nos critérios de avaliação do CNPq.

Figura 3 - Participação em Grupos de Pesquisa

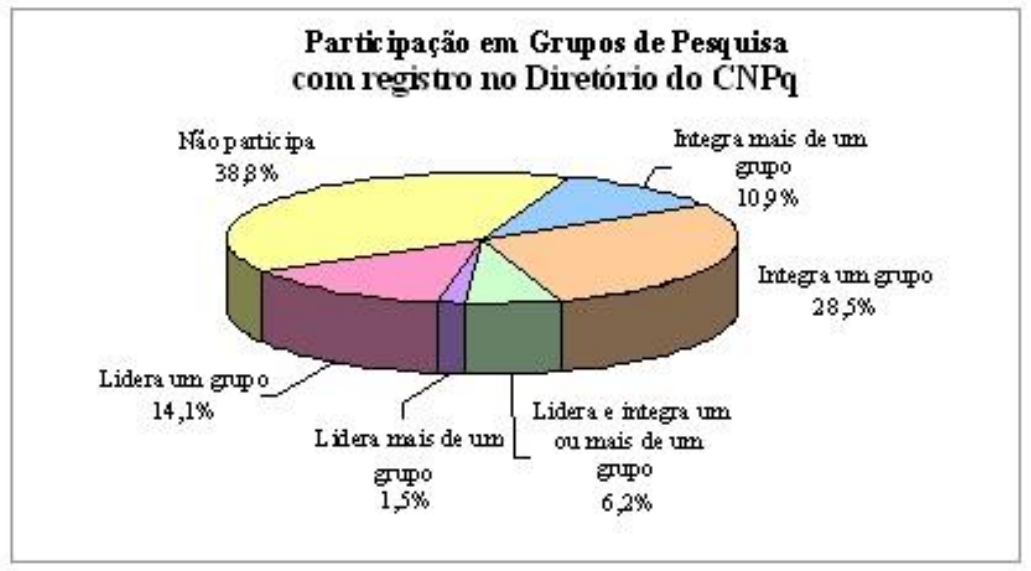

Fonte: Elaborado pela autora.

\section{Inserção Na Atividade De Pesquisa: A Obtenção De Financiamento}

Um conjunto de questões visava levantar elementos que pudessem favorecer a análise da inserção dos professores na atividade de pesquisa e a obtenção de financiamento para pesquisa. Os dados do inquérito apontam que nos últimos três anos $42,4 \%$ dos professores haviam obtido financiamento para fazer pesquisa e $57,6 \%$ indicaram que não obtiveram financiamento para pesquisa, o que pode significar não ter a pesquisa como atividade acadêmica formal ou realizar pesquisa sem financiamento, o que é pouco plausível. Ainda que $58,5 \%$ de professores indicaram algum percentual diferente de zero de carga horária destinada à atividade de pesquisa, apenas $42,4 \%$ teve acesso a financiamento.

A principal fonte de financiamento é pública (49,3\%), seguida de financiamento da própria universidade $(20,1 \%)$. Do total, $15,3 \%$ têm financiamento publico privado e da própria universidade e 10,4\% têm financiamento público e privado. O financiamento privado é obtido somente por $4,9 \%$ dos pesquisados.

Quando a análise é feita por IES observamos que dos $42,4 \%$ dos professores que obtiveram financiamento para pesquisa, a maioria está na UFPA, universidade que tem a maior densidade de doutores em tempo integral ou em regime de tempo integral e dedicação exclusiva, assim como possui a maior densidade de professores com contrato de trabalho único, ou seja, com somente uma IES. 
Quando fazemos a correlação entre regime de trabalho e obtenção de financiamento para pesquisa o valor $\mathrm{p}=0$, 000 no Teste Qui Quadrado nos possibilita estabelecer a associação entre regime de trabalho e obtenção de financiamento, assim também entre o fato de o professor ter contrato de trabalho com somente uma IES, o que possibilita dedicação centrada em uma instituição.

Tabela 7 - Relação entre obtenção de financiamento para pesquisa e regime de trabalho

\begin{tabular}{l|c|c|c}
\hline \multirow{2}{*}{ Regime de Trabalho } & \multicolumn{2}{|c|}{$\begin{array}{c}\text { Obtenção de financiam ento para } \\
\text { pesquisa nos últimos três anos }\end{array}$} & \multirow{2}{*}{ Total } \\
\cline { 2 - 3 } & Não $\%$ & $\operatorname{Sim} \%$ & \\
\hline Tempo Integ ral & 46,9 & 30,6 & $40,0 \%$ \\
\hline Tempo Integ ral/Dedicaçăo Exclusiva & 38,3 & 61,1 & $47,9 \%$ \\
\hline Tempo Parcial & 14,8 & 8,3 & $12,1 \%$ \\
\hline Total & $100,0 \%$ & $100,0 \%$ & $100,0 \%$ \\
\hline
\end{tabular}

Valor $\mathrm{p}=0,000$

Fonte: Elaborado pela autora.

Tabela 8 - Relação entre obtenção de financiamento para pesquisa e situação de contrato de trabalho em uma ou mais IES ou empresas

\begin{tabular}{|c|c|c|c|}
\hline \multirow{2}{*}{ Situação do contra to de trabalho } & \multicolumn{2}{|c|}{$\begin{array}{l}\text { Obtenção de financiamento para } \\
\text { pesquisa nos últimos três anos. }\end{array}$} & \multirow{2}{*}{ Total } \\
\hline & Não & Sim & \\
\hline $\begin{array}{l}\text { Tinha con trato de trabalho em } \\
\text { somente uma IES }\end{array}$ & $52,1 \%$ & $77,1 \%$ & $62,6 \%$ \\
\hline $\begin{array}{l}\text { Tinha con trato tambèm em } \\
\text { empreendimento privado ou outro } \\
\text { cargo em empresa publica ou } \\
\text { privada (atividade. nâo acadêmica). }\end{array}$ & $25,5 \%$ & $9,7 \%$ & $18,8 \%$ \\
\hline $\begin{array}{l}\text { Tinha de contrato de trabatho } \\
\text { tambem com outra IES privada } \\
\text { (atividade. academica). }\end{array}$ & $16,8 \%$ & $6,9 \%$ & $12,6 \%$ \\
\hline $\begin{array}{l}\text { Tinha de con trato de trabalho } \\
\text { tambem com outra } \mathbb{E S} \text { puiblica } \\
\text { (atividade. acadêmica). }\end{array}$ & $5,6 \%$ & $6,3 \%$ & $5,9 \%$ \\
\hline Total & $100,0 \%$ & $100,0 \%$ & $100,0 \%$ \\
\hline
\end{tabular}

Valor $p=0,000$

Fonte: Elaborado pela autora.

Quando na análise enfocamos a Titulação, a maior qualificação (o nível de Doutorado) possibilita aos professores o maior acesso a financiamento para pesquisa e o valor $p=$ o, 000 no Teste Qui-Quadrado confirma a associação entre estas variáveis - titulação e obtenção de financiamento para pesquisa. Mesmo quando a análise considera apenas os $42,4 \%$ dos professores que obtiveram financiamento, $66,7 \%$ são Doutores, $29,2 \%$ são Mestres e 4,2\% são Especialistas. A tabela a seguir apresenta a relação entre titulação e obtenção de financiamento para pesquisa. 
Tabela 9 - Relação entre obtenção de financiamento para pesquisa e titulação

\begin{tabular}{l|c|c|c|c|c}
\hline $\begin{array}{c}\text { Obtenção de } \\
\text { financiamento }\end{array}$ & \multicolumn{5}{|c|}{ Titulação \% } \\
\cline { 2 - 6 } $\begin{array}{c}\text { para pesquisa nos } \\
\text { últimos três anos }\end{array}$ & Doutorado & Mestrado & Especialização & Graduação & Total \\
\hline Não & 29,9 & 70,6 & 88,0 & 100,0 & $57,6 \%$ \\
\hline Sim & 70,1 & 29,4 & 12,0 & 0,0 & $42,4 \%$ \\
\hline Total & $100,0 \%$ & $100,0 \%$ & $100,0 \%$ & $100,0 \%$ & $100,0 \%$ \\
\hline
\end{tabular}

Valor $\mathrm{p}=0,000$

Fonte: Elaborado pela autora.

Tempo de carreira não se evidencia como um fator ao qual possa estar associado a obtenção de financiamento para pesquisa, como indicado na tabela a seguir.

Tabela 10 - Relação entre obtenção de financiamento e tempo na carreira acadêmica

\begin{tabular}{l|c|c|c}
\hline \multirow{2}{*}{$\begin{array}{c}\text { Tempo na carreira } \\
\text { a cademica }\end{array}$} & \multicolumn{2}{|c|}{$\begin{array}{c}\text { Obtenção de financiam ento para pesquisa nos últimos } \\
\text { três anos }\end{array}$} & \multirow{2}{*}{ Total } \\
\cline { 2 - 3 } & Não & Sim & \\
\hline 1 a 5 anos & $15,3 \%$ & $13,2 \%$ & $14,4 \%$ \\
\hline 6 a 15 anos & $30,1 \%$ & $35,4 \%$ & $32,4 \%$ \\
\hline 16 a 25 anos & $35,7 \%$ & $31,9 \%$ & $34,1 \%$ \\
\hline 26 an os ou mais & $18,9 \%$ & $19,4 \%$ & $19,1 \%$ \\
\hline Total & $100,0 \%$ & $100,0 \%$ & $100,0 \%$ \\
\hline Valor $\mathrm{p}=0,719$ & \multicolumn{2}{|}{}
\end{tabular}

Fonte: Elaborado pela autora.

\section{EM CONCLUSÃO}

Em vista das novas condições em que se produz o exercício da profissão acadêmica e o trabalho dos professores universitários, tem havido transformações na organização do trabalho acadêmico, o qual assume características tais como: intensificação e pressão para aumento da carga de trabalho; maior complexidade sob a influência das transformações nos processos de ensino, da diversificação das demandas do alunado, das demandas para assumir novas funções e responsabilidades ou encargos; necessidade de produção científica com publicação acadêmica qualificada e obtenção de recursos ou financiamento para pesquisa e reconhecimento, visibilidade, reputação acadêmica nacional e internacional na sua área de conhecimento.

O trabalho em redes científicas e de cooperação nacionais e internacionais é outra característica marcante da profissão acadêmica hoje, por trazer os benefícios da partilha de recursos, de conhecimento e tecnologia e favorecimento das relações com as agências de financiamento, além do aumento de eficiência para realização de projetos conjuntos com agregação de esforços e o fortalecimento da pesquisa na temática da rede. Congregar experiência dos membros das redes, pelas articulações que estas possibilitam resulta em aumento da eficiência pela realização de projetos articulados e facilita as publicações e o acesso a recursos financeiros. Essa é a forma de trabalho utilizada pela maioria dos pesquisados assim como é usual a participação 
em grupos de pesquisa com registro em base nacional de dados, o Diretório de Grupos de Pesquisa do CNPq.

Não sendo mais a detentora do saber a ser transmitido e do conhecimento a ser produzido, a universidade compartilha com outras instituições essa função, o que abre um desafio de adaptabilidade a essa nova realidade.

Artigo recebido em 08/07/2014 e aprovado em 24/09/2014

\section{REFERÊNCIAS}

BALBACHEVSKY, E. A profissão acadêmica no Brasil: as múltiplas facetas de nosso sistema de ensino superior. Brasília: FUNADESP, 1999.

BALBACHEVSKY, E. Carreiras e contexto institucional no sistema de ensino superior brasileiro. Sociologias, Rio Grande do Sul, n. 17, p. 158-189, 2007.

BALBACHEVSKY, E.; SCHWARTZMAN, S. Brazil: a typology of the academic profession and the impact of recent government institutional policies. In: TEICHLER, U.; LOCKE, $\mathrm{W}$. The changing conditions for the academic work and careers in select countries. Kassel: International Centre for Higher Education, 2007, p. 93-111.

BECHER, T.; TROWLER, P.R. Academic tribes and territories. Buckinghan: Open University Press, 2001.

ENDERS, J.; MUSSELIN,C. Back to the future? The academic professions in the $21^{\text {st }}$ Century. In: HIGHER EDUCATION TO 2030. Demography, Centre for Educational Research and Innovation. Paris: OECD, 2008, v. 1, p. 125-150

GALAZ FONTES, J.F.; GIL ANTON, M. La profesión académica em Mexico: un oficio en proceso de reconfiguración. Revista Electrônica de Investigación Educativa, v. 11, n. 2, 2009. Disponível em: <http://redle.uabc.mc>. Acesso em: 13 out. 2010.

LATOUR, B. A vida em laboratório: a produção dos fatos científicos. Rio de Janeiro: Relume Dumará, 1984.

MALDONADO, A.M. The influence of international organizations in the field of Higher Education in México, Dissertação. Boston: College, 2004

PEDRÓ, F.; SALA, S. La profesión académica em los países de la Unión Europea. Estado actual y tendências de reforma. [S.I.]: Universidad Pompeu Fabra. Departamento de Ciencias Políticas y Sociales, 2002

RHOADES, G.; SPORN, B. Quality assurance in Europe and the U.S.: professional and political economic framing of Higher Education policy. Higher Education, v. 43, n. 3, p. 355-390, 2002.

SCHWARTZMAN, S. A profissão acadêmica no Brasil. Versão preliminar em Língua Portuguesa de "The academic profession in Brazil". In: ALBACK, P.G. The international academic profession: portraits of 14 countries. Princepton,NY: Carnegie Foundation for Advancement of Teaching, 1997.

SGUISSARDI, V.; SILVA JÚNIOR, J.R. Trabalho intensificado nas federais: PósGraduação e produtivismo acadêmico. São Paulo: Xamã, 2009.

WATERS, L. Inimigos da esperança. Publicar, perecer e o eclipse da erudição. Tradução de L. H. de A. Dutra. São Paulo: UNESP, 2006. 